\title{
Evidence for weak oceanic transform faults
}

\author{
Mark D. Behn \\ MIT-WHOI Joint Program, Woods Hole, Massachusetts, USA
}

Jian Lin

Department of Geology and Geophysics, Woods Hole Oceanographic Institution, Woods Hole, Massachusetts, USA

\begin{abstract}
Maria T. Zuber
Department of Earth, Atmospheric and Planetary Sciences, Massachusetts Institute of Technology, Cambridge, Massachusetts, USA
\end{abstract}

Received 5 June 2002; revised 12 August 2002; accepted 13 August 2002; published 27 December 2002.

[1] We present the results of a series of 3-D boundary element calculations to investigate the effects of oceanic transform faults on stress state and fault development at adjacent mid-ocean ridge spreading centers. We find that the time-averaged strength of transform faults is low, and that on time scales longer than a typical earthquake cycle transform faults behave as zones of significant weakness. Specifically, mechanical coupling of only $\sim 5 \%$ best explains the observed patterns of strike-slip and oblique normal faulting near a ridge-transform intersection. On time scales shorter than a typical earthquake cycle, transient "locked" periods can produce anomalous reverse faulting similar to that observed at the inside corner (IC) of several slow-spreading ridge segments. Furthermore, we predict that extensional stresses will be suppressed at the IC due to the shear along the transform resisting ridge-normal extension. This implies that an alternative mechanism is necessary to explain the preferential normal fault growth and enhanced microseismicity observed at many ICs. INDEX TERMS: 3035 Marine Geology and Geophysics: Midocean ridge processes. Citation: Behn, M. D., J. Lin, and M. T. Zuber, Evidence for weak oceanic transform faults, Geophys. Res. Lett., 29(24), 2207, doi:10.1029/2002GL015612, 2002.

\section{Introduction}

[2] Oceanic transform faults are fundamental features of the mid-ocean ridge spreading system. Near the intersection of a slow-spreading ridge and a transform fault, axial topography is consistently asymmetric, with crust on the inside-corner (IC) elevated relative to that on the outsidecorner (OC) [e.g., Karson and Dick, 1983] (Figure 1). Similar asymmetry is also reflected in the pattern of seafloor faulting and abyssal hill fabric. In particular, faults extending from the segment center into IC crust curve sharply in the offset direction, while faults extending into OC crust typically remain parallel to the ridge (Figure 1). These observations are consistent with teleseismic events indicating oblique normal faulting mechanisms near the end of several segments on the Mid-Atlantic Ridge (MAR) [Huang and Solomon, 1988]. Evidence from microearthquake studies [Wolfe et al., 1995; Barclay et al., 2001] and hydroacoustic monitoring [Smith et al., 2002] suggests that ICs

Copyright 2002 by the American Geophysical Union. 0094-8276/02/2002GL015612\$05.00 may be more seismically active than OCs. ICs have also been associated with several examples of anomalous reverse faulting mechanisms, which are in sharp contrast to the otherwise ridge-normal extensional stress field [Engeln et al., 1986; Wolfe et al., 1993].

[3] The observed asymmetry in seismicity and normal fault orientation near the ends of slow-spreading ridge segments is indicative of a deviation in the regional stress field from otherwise ridge-normal extension. Shearing along an active transform fault has been proposed to perturb the stress field sufficiently to explain both the rotation and asymmetry in faulting at segment ends. This mechanism has been quantified by numerical studies that calculate the relative amount of stress rotation as a function of the ratio between the ridge-normal extensional stress and the shear stress along the transform [Fujita and Sleep, 1978; Phipps Morgan and Parmentier, 1984]. However, by specifying stresses directly on the ridge axis and transform fault, these models do not provide an estimate of the magnitude of mechanical coupling across the transform.

[4] In this study we perform a series of three-dimensional (3-D) boundary element calculations to examine the effects of mechanical coupling along oceanic transform faults on stress state and fault development at oceanic spreading centers. Optimal fault planes are calculated as a function of the conditions on the transform and our results are discussed in relation to observed seismicity, transform strength, and fault orientation at ridge-transform intersections.

\section{Model Setup}

[5] We model the stress field near a transform fault using a 3-D boundary element model [Gomberg and Ellis, 1994]. The geometry of the model domain is shown in Figure 2a. The north, south, and basal boundaries of the model space are defined to be shear stress free with no normal displacement, while the top boundary is stress free. In reality, the zero shear stress region at the base of the plate (which can be approximated by the brittle/ductile transition) is likely to increase with crustal age. However, sensitivity tests show that our numerical solutions are not strongly dependent on the plate thickness, $Z_{\mathrm{o}}$, and thus our predictions for a uniform plate thickness are a reasonable approximation for stresses in the study region.

[6] Steady-state plate motion is simulated by specifying displacements, $\mathrm{U}_{\mathrm{o}}$ and $-\mathrm{U}_{\mathrm{o}}$, on the east and west boundaries 


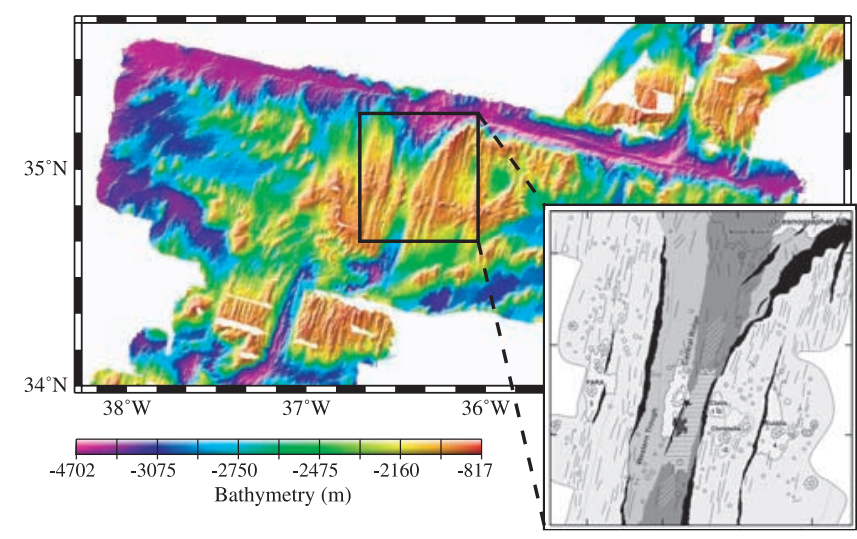

Figure 1. Bathymetry of the $\mathrm{OH}-1$ and $\mathrm{OH}-2$ segments south of the Oceanographer Fracture Zone at the MAR [Rabain et al., 2001]. Inset shows the geologic interpretation of the OH-1 segment by Gràcia et al. [1999] based on bathymetry, acoustic backscattering, submersible observations, and rock samples. Major fault scarps are shown in black. Figure adapted from Rabain et al. [2001] and Gràcia et al. [1999].

of the model space, respectively, and on both sides of each ridge axis (Figure 2b). Seismic moment studies [Solomon et al., 1988] and measurements of cumulative fault throw from the Broken Spur segment of the MAR [Escartin et al., 1999] suggest that $15-20 \%$ of sea-floor spreading is accommodated by extensional faulting with the rest by magmatic emplacement. Therefore, in addition to the steady-state displacement field we superimpose a far-field extensional strain, $\varepsilon_{\text {f.f., }}$ corresponding to $20 \%$ total strain. The sensitivity

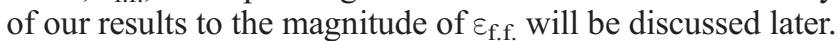

[7] A shear displacement discontinuity, $\mathrm{D}_{\mathrm{s}}$, is specified along the transform fault, with $\mathrm{D}_{\mathrm{s}}=2 \mathrm{U}_{\mathrm{o}}(1-\chi)$. The factor $\chi$ is used to simulate the coupling of the two plates across the transform, with $\chi=0$ corresponding to total decoupling or free slip along the transform, and $\chi=1$ representing a completely locked fault. We assume zero normal displacement discontinuity across the transform fault (i.e., $\mathrm{D}_{\mathrm{n}}=0$ ). In reality, coupling across a transform fault will vary as a function of time. We envision that immediately before a large earthquake the transform should behave in a more locked manner, exerting larger shear stresses on the adjacent plates. In contrast, after a major earthquake the accumulated shear stresses are likely to be released and the transform will behave in a more decoupled manner.

[8] The predicted principal deviatoric stress orientations are used to estimate optimal fault planes throughout the model space. Seismic observations of focal mechanisms at slow-spreading ridges show most normal faulting events to occur at dip angles of $45^{\circ}$ and most strike-slip events to be oriented parallel to the trend of the transform fault [e.g., Thatcher and Hill, 1995]. These observations imply that the coefficient of friction in oceanic lithosphere is very low, and we use $\mu=0$ to calculate the orientation of failure planes throughout the model space. A higher coefficient of friction would result in steeper dip angles for the predicted normal faults. In this linear elastic analysis, the directions of the principal deviatoric stresses remain constant for all values of $\mathrm{U}_{\mathrm{o}}$. Therefore, the orientation of the optimal fault planes is independent of the absolute magnitude of the far-field displacement.

[9] To assess the relative potential for failure on a predicted fault plane, we calculate the ratio of shear to normal stress $\tau_{\mathrm{dev}} / \sigma_{\mathrm{dev}+\text { lith }}$ resolved on the predicted plane incorporating both deviatoric and lithostatic components. We calculate $\sigma_{\text {lith }}=\rho g h$ throughout the model space, where $\rho$ is the average lithospheric density, $g$ is acceleration due to gravity, and $h$ is the depth to the $600^{\circ} \mathrm{C}$ isotherm approximated from a half-space cooling model. We note that a half-space model results in a more abrupt temperature change across the transform than would a passive flow thermal model. However, the difference in $h$ calculated from these two approaches does not significantly affect our numerical results. Because the lithosphere is observed to have a finite thickness at the ridge axis, the minimum depth of the $600^{\circ} \mathrm{C}$ isotherm is set to $6 \mathrm{~km}$. Note that while the orientations of the optimal fault planes were independent of the far-field displacement, $\tau_{\mathrm{dev}} / \sigma_{\mathrm{dev}}+$ lith increases with increasing values of $U_{\mathrm{o}}$ due to the larger magnitude of the deviatoric stresses relative to $\sigma_{\text {lith }}$.

\section{Results}

[10] Figure 3 illustrates the calculated optimal fault planes as a function of the mechanical coupling parameter, $\chi$, for a $100-\mathrm{km}$ transform. In the case of complete decoupling $(\chi=0)$, no shear stresses are generated along the transform and the only source of deviatoric stress is ridge-normal tension generated from the far-field strain (Figure 3a). The calculated optimal fault planes are uniformly normal faulting mechanisms with ridge parallel

a)

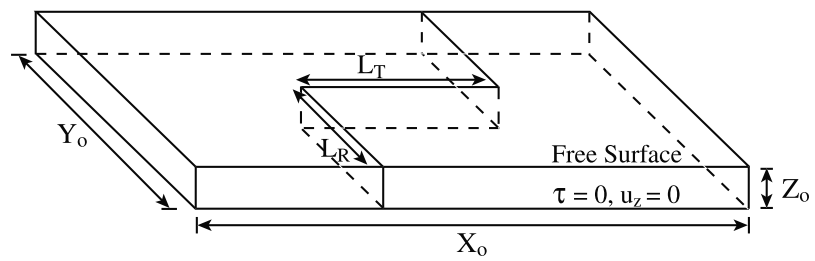

b)

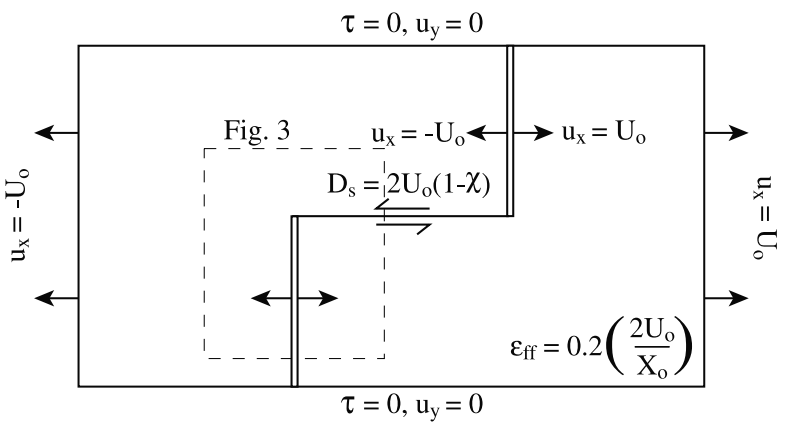

Figure 2. (a) Model setup and (b) boundary conditions for 3-D boundary element analysis. The model dimensions are $\mathrm{X}_{\mathrm{o}}=240 \mathrm{~km}, \mathrm{Y}_{\mathrm{o}}=160 \mathrm{~km}$, and $\mathrm{Z}_{\mathrm{o}}=15 \mathrm{~km}$ with $\mathrm{L}_{\mathrm{R}}=120$ $\mathrm{km}$ and $\mathrm{L}_{\mathrm{T}}=100 \mathrm{~km}$. Boundary conditions and driving forces are described in text. All calculations were performed with a Young's modulus, E, of $70 \mathrm{GPa}$ and a Poisson's ratio, $\nu$, of 0.25 . 

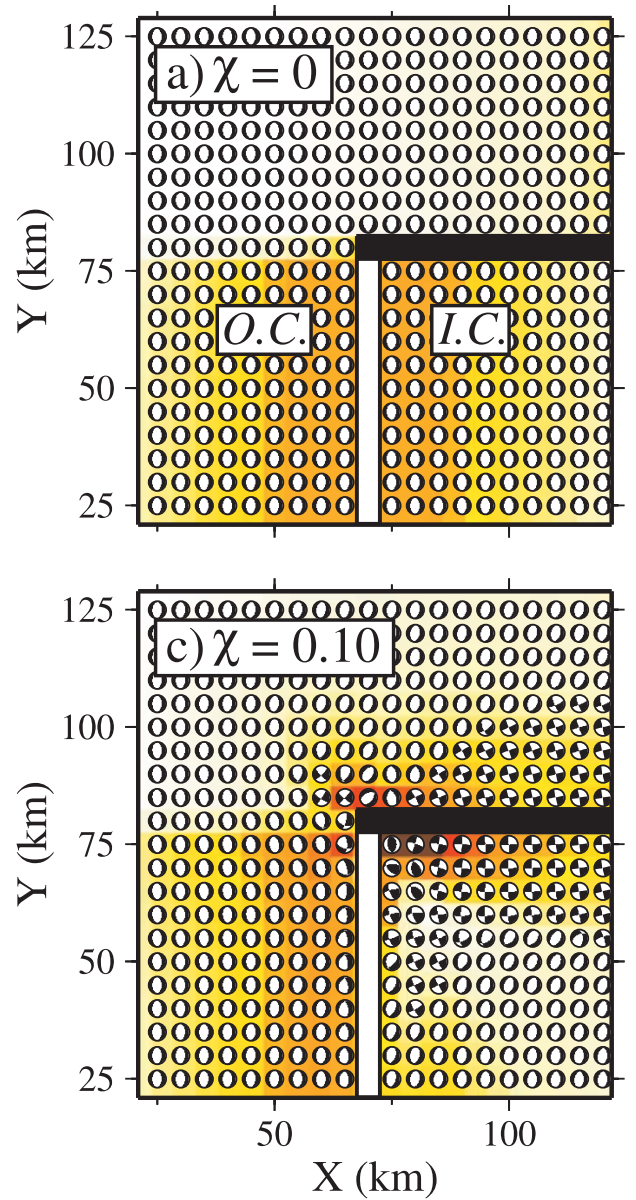
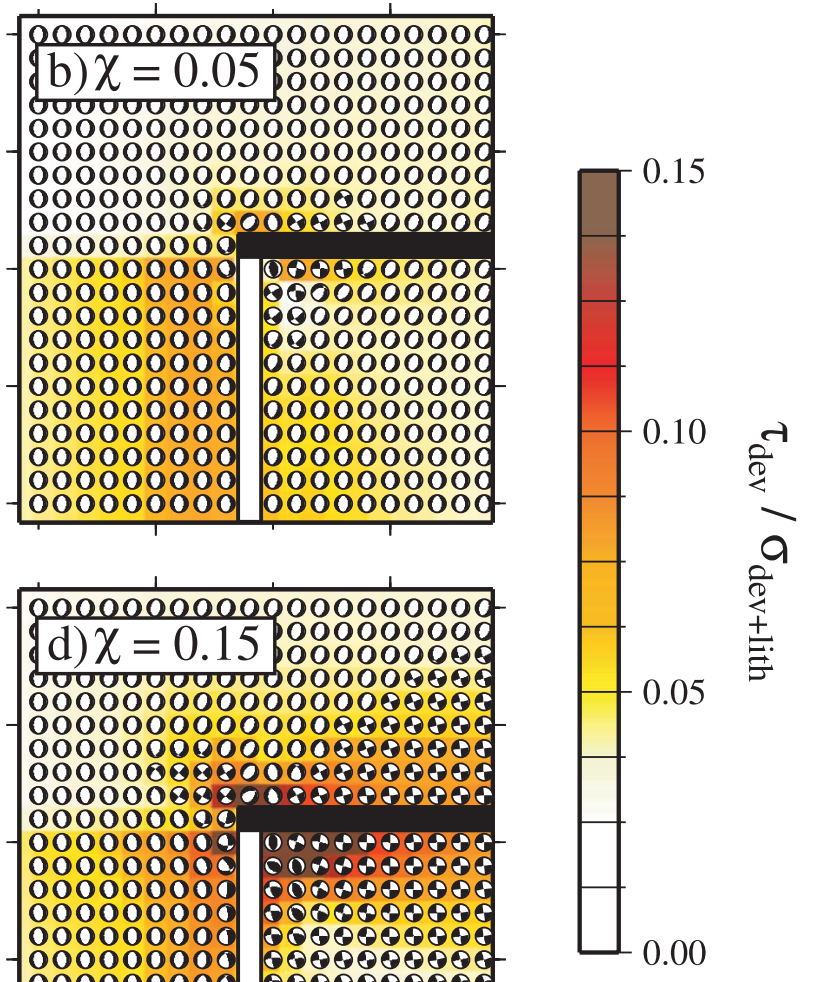

O00000000

000000000 OOOOOOOOA

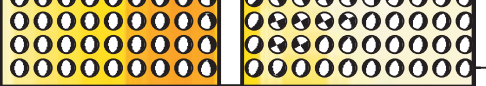

50

100

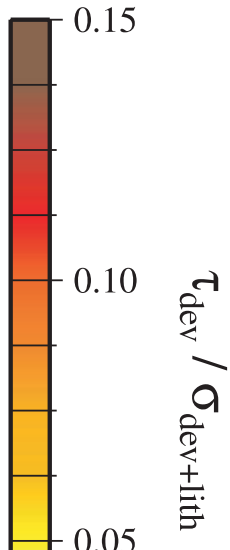

0.00

Figure 3. Effect of the mechanical coupling parameter, $\chi$, on the style of faulting near an oceanic transform fault. Orientations of calculated optimal fault planes for (a) $\chi=0$, (b) $\chi=0.05$, (c) $\chi=0.10$, and (d) $\chi=0.15$. Deformation is driven by a far-field displacement $U_{o}=100 \mathrm{~m}$, equivalent to 10,000 years of spreading at a half-rate of $1 \mathrm{~cm} / \mathrm{yr}$. Optimal fault planes are evaluated at a depth of $4 \mathrm{~km}$, consistent with the average depth of faulting near the axis of the MAR from microseismicity studies [Wolfe et al., 1995; Barclay et al., 2001]. Rectangular boxes show location of ridge segment (white) and transform fault (black). Color shading indicates the relative magnitude of $\tau_{\mathrm{dev}} / \sigma_{\mathrm{dev}}+$ lith. A coupling parameter of $\chi=$ 0.05 most closely matches the observed fault orientations and focal mechanisms at slow-spreading mid-ocean ridges.

orientations, and the magnitude of $\tau_{\mathrm{dev}} / \sigma_{\mathrm{dev}}+$ lith is greatest near the ridge axes, where the lithosphere is thinnest.

[11] Increasing $\chi$ to 0.05 generates shear stresses along the transform, resulting in a number of changes in the predicted pattern of stress (Figure 3b). First, the orientation of the predicted normal faulting mechanisms at the IC and along the transform are rotated clockwise with respect to the spreading ridge. Second, a narrow region of strike-slip faulting forms near the end of the transform, extending $\sim 20 \mathrm{~km}$ east from the ridge-transform intersection and $\sim 10 \mathrm{~km}$ north and south of the transform fault trace. Finally, the magnitude of $\tau_{\mathrm{dev}} / \sigma_{\mathrm{dev}}+$ lith on the predicted normal fault planes becomes asymmetrical across the ends of the ridge segments, with higher values predicted on the OCs. This somewhat surprising effect is caused by the induced shear along the transform resisting the far-field extensional stresses. Immediately adjacent to the ridgetransform intersection these shear stresses are sufficient to generate a reverse faulting mechanism, although the value of $\tau_{\mathrm{dev}} / \sigma_{\mathrm{dev}}+$ lith on the predicted fault plane is low.

[12] As the coupling parameter, $\chi$, is increased to values of 0.10 and 0.15 , strike-slip deformation is predicted to dominate near the transform (Figures $3 \mathrm{c}$ and $3 \mathrm{~d}$ ). For $\chi=$ 0.15 , strike-slip faulting is predicted in a $\sim 70-\mathrm{km}$ wide north-south region around the center of the transform $(\mathrm{x}=$ $120 \mathrm{~km}$ ) and to extend $\sim 50 \mathrm{~km}$ south along the IC side of the ridge axis. Reverse faulting is predicted over a larger portion of the IC, with several of the fault planes associated with high values of $\tau_{\mathrm{dev}} / \sigma_{\mathrm{dev}}+$ lith. The dominant style of deformation on the OC remains ridge-parallel normal faulting, with a slight counter-clockwise rotation in fault orientation near the segment end.

[13] Observed seismicity at oceanic spreading centers indicates that strike-slip faulting is confined to a narrow region (20-25 $\mathrm{km}$ wide) around an active transform and is rarely observed along the axis of an adjacent spreading center [Engeln et al., 1986; Boettcher and Jordan, 2001]. Furthermore, the presence of large rotated normal faults at many ICs indicates that significant extensional rather than compressional or strike-slip strain must be accommodated on these faults. These observations are most consistent with predictions for coupling parameters less than 0.10 , and thus imply that the time-averaged strength of oceanic transform faults is low. 
[14] On time scales shorter than a typical earthquake cycle, however, coupling across oceanic transforms may experience significant temporal variability. Before a major earthquake we envision that some transform faults may exhibit a larger coupling parameter. Such "locked" periods could explain the presence of the anomalous reverse faulting mechanisms observed at a number of ICs [Engeln et al., 1986; Wolfe et al., 1993]. On such short time scales, stresses may also vary as a function of individual magmatic events. The predicted pattern of stress is a function of the relative ratio of $\chi$ to the magnitude of the far-field extensional strain, $\varepsilon_{\text {f.f. }}$. For example, increasing $\varepsilon_{\text {f.f. }}$ by a factor of two would produce the same effect on fault style as decreasing $\chi$ by one-half. However, even for $50 \%$ amagmatic strain $\left(\varepsilon_{\text {f.f. }}=\right.$ $\left.0.5\left(2 \mathrm{U}_{\mathrm{o}} / \mathrm{X}_{\mathrm{o}}\right)\right)$, the maximum coupling consistent with the observations is on the order of $\chi=0.10$ or less.

[15] Based on a comparision of observed seafloor fabrics and the solutions of a 2-D thin plate model, Phipps Morgan and Parmentier [1984] proposed that the ratio of average normal stress at the ridge axis to shear stress along the transform $\left(\sigma_{\mathrm{R}} / \sigma_{\mathrm{T}}\right)$ is in the range of 3 to 5 . For $\chi=0.05$, the ratio of $\sigma_{\mathrm{T}}$ at the center of the transform to $\sigma_{\mathrm{R}}$ at the ridge axis is $\sim 3.2$. In contrast, for $\chi=0.15$ this ratio decreases to only $\sim 1.1$. Thus, our 3-D results are consistent with the 2-D thin plate solutions of Phipps Morgan and Parmentier [1984], and show that $\sigma_{\mathrm{R}} / \sigma_{\mathrm{T}}$ ratios of $3-5$ correspond to mechanical coupling across a transform of $\leq 5 \%$.

\section{Summary}

[16] Our results illustrate that the pattern of faulting and seismicity observed near ridge-transform intersections is most consistent with $\sim 5 \%$ mechanical coupling across the transform (i.e., coupling coefficient $\chi=0.05$ ). This implies that the additional $95 \%$ of the shear strain must dissipate rapidly relative to the earthquake cycle, either through aseismic creep or slow earthquakes. These results are consistent with independent findings from seismic moment studies of oceanic transform faults. Okal and Langenhorst [2000] and Boettcher and Jordan [2001] found that the cumulative seismic moment release on most oceanic transforms can account for only $10-15 \%$ of the total slip predicted from kinematic models. These observations are in sharp contrast to some major continental strike-slip systems, where studies have found little evidence for seismic deficits on the Anatolian Fault [e.g., Kiratzi, 1993] and the southern San Andreas Fault [e.g., Stein and Hanks, 1998]. Thus, it appears that most oceanic transform faults may be characterized by greater amounts of aseismic slip than some continental strike-slip faults.

[17] On time scales shorter than a typical earthquake cycle, however, coupling along oceanic transforms may experience significant temporal variations. Transient "locked" periods may explain the presence of anomalous reverse faulting mechanisms observed at some ICs. Another interesting prediction of our model is that ICs are not characterized by enhanced extensional stresses relative to OCs. Instead, the opposite effect occurs, with shear stresses along the transform calculated to suppress ridge-normal extension at ICs. This indicates that an alternative mecha- nism is necessary to explain the preferential normal fault growth and microseismicity observed in these regions.

[18] Acknowledgments. We are grateful to Joan Gomberg, who provided the 3-D boundary element modeling program used in this study. We also thank Seth Stein for his constructive review and Margaret Boettcher, Greg Hirth, Jeff McGuire, and Laurent Montési for helpful discussions. Research was supported by NSF Grant EAR-0003888 (J. Lin) and NASA Grants NAG5-4555 and NAG5-9143 (M.T. Zuber). Contribution 10739 of Woods Hole Oceanographic Institution.

\section{References}

Barclay, A., D. Toomey, and S. Solomon, Microearthquake characteristics and crustal Vp/Vs structure at the Mid-Atlantic Ridge, $35^{\circ} \mathrm{N}, J$. Geophys. Res., 106, 2017-2034, 2001.

Boettcher, M., and T. Jordan, Seismic behavior of oceanic transform faults, Eos. Trans. AGU, 82(47), Fall Meet. Suppl., Abstract S32E-07, 2001.

Engeln, J., D. Wiens, and S. Stein, Mechanisms and depths of Atlantic transform earthquakes, J. Geophys. Res., 91, 548-577, 1986.

Escartín, J., P. Cowie, R. Searle, S. Allerton, N. Mitchell, C. Macleod, and A. Slootweg, Quantifying tectonic strain and magmatic accretion at a slow spreading ridge segment, Mid-Atlantic Ridge, $29^{\circ} \mathrm{N}$, J. Geophys. Res., 104, 10,421-10,437, 1999.

Fujita, K., and N. Sleep, Membrane stresses near mid-ocean ridge-transform intersections, Tectonophys., 50, 207-221, 1978.

Gomberg, J., and M. Ellis, Topography and tectonics of the central New Madrid seismic zone: Results of numerical experiments using a threedimensional boundary element program, J. Geophys. Res., 99, 20,29920,310, 1994

Gràcia, E., D. Bideau, R. Hekinian, and Y. Lagabrielle, Detailed geological mapping of two contrasting second-order segments of the Mid-Atlantic Ridge between Oceanographer and Hayes fracture zones $\left(33^{\circ} 30^{\prime} \mathrm{N}-\right.$ $\left.35^{\circ} \mathrm{N}\right)$, J. Geophys. Res., 104, 22,903-22,921, 1999.

Karson, J., and H. Dick, Tectonics of ridge-transform intersections at the Kane fracture zone, Mar. Geophys. Res., 6, 51-98, 1983.

Kiratzi, A., A study of the active crustal deformation of the North and East Anatolian Fault Zones, Tectonophys., 225, 191-203, 1993.

Okal, E., and A. Langenhorst, Seismic properties of the Etanin Transform System, South Pacific, Phys. Earth Planet. Int., 8119, 185-208, 2000.

Phipps Morgan, J., and E. Parmentier, Lithospheric stress near a ridgetransform intersection, Geophys. Res. Lett., 11, 113-116, 1984.

Pockalny, R., P. Gente, and R. Buck, Oceanic transverse ridges: A flexural response to fracture-zone-normal extension, Geology, 24, 71-74, 1996.

Rabain, A., M. Cannat, J. Escartín, G. Pouliquen, C. Deplus, and C. Rommevaux-Jestin, Focused volcanism and growth of a slow-spreading segment (Mid-Atlantic Ridge, $35^{\circ} \mathrm{N}$ ), Earth Planet. Sci. Lett., 185, 211-224, 2001.

Smith, D., M. Tolstoy, C. Fox, D. Bohnenstiehl, H. Matsumoto, and M. Fowler, Hydroacoustic monitoring of seismicity at the slow-spreading Mid-Atlantic Ridge, Geophys. Res. Lett., 29, 10.1029/2001GL013912, 2002.

Solomon, S., P. Huang, and L. Meinke, The seismic moment budget of slowly spreading ridges, Nature, 334, 58-60, 1988.

Stein, R., and T. Hanks, $M \geq 6$ Earthquakes in southern California during the 20th Century: No evidence for a seismicity or moment deficit, Bull. Seismol. Soc. Amer., 88, 635-652, 1998.

Thatcher, W., and D. Hill, A simple model for the fault-generated morphology of slow-spreading mid-oceanic ridges, J. Geophys. Res., 100, $561-$ 579,1995

Wolfe, C., E. Bergman, and S. Solomon, Oceanic transform earthquakes with unusual mechanisms or locations: Relation to fault geometry and state of stress in adjacent lithosphere, J. Geophys. Res., 98, 16,18716,211, 1993.

Wolfe, C., G. Purdy, D. Toomey, and S. Solomon, Microearthquake characteristics and crustal velocity structure at $29^{\circ} \mathrm{N}$ on the Mid-Atlantic Ridge: The architecture of a slow spreading segment, J. Geophys. Res., 100, 24,449-24,472, 1995.

M. D. Behn, MIT/WHOI Joint Program, Woods Hole Oceanographic Institution, Woods Hole, MA 02543, USA. (mbehn@mit.edu)

J. Lin, Department of Geology and Geophysics, Woods Hole Oceanographic Institution, Woods Hole, MA 02543, USA. (jlin@whoi.edu)

M. T. Zuber, Department of Earth, Atmospheric and Planetary Sciences, Massachusetts Institute of Technology, Cambridge, MA 02139, USA (zuber@mit.edu) 